\title{
INTERVENÇÕES TÁTICAS CICLOVIÁRIAS A utilização da bicicleta como modal de transporte na cidade de João Pessoa
}

\author{
Mirna Sousa Linhares \\ Universidade Federal da Paraíba - UFPB \\ Orientadora Amélia de Farias Panet Barros \\ mirna_linhares@hotmail.com
}

\begin{abstract}
RESUMO
No Brasil, um dos principais elementos a influenciar a estrutura das cidades é o modelo de mobilidade centrado no transporte motorizado individual. Como forma de embate aos paradigmas urbanos contemporâneos, práticas urbanas criativas que chegam a partir de iniciativas populares (bottom-up) para abordar problemas do cotidiano são uma crescente tendência mundial, e tem grande potencial de transformação dos espaços públicos. O trabalho teve como objetivo principal propor o uso do urbanismo tático como ferramenta participativa no planejamento cicloviário. A concepção da metodologia teve como princípio a análise do Plano Cicloviário de João Pessoa através de um processo metodológico colaborativo, o qual deu suporte para escolha e aplicação das intervenções. A pesquisa revelou que a inserção do urbanismo tático como ferramenta formal no planejamento urbano pode fomentar um novo olhar sobre as estratégias de planejamento e, consequentemente, impulsionar um processo verdadeiramente participativo na produção do espaço urbano.
\end{abstract}

Palavras chave: Urbanismo tático, planejamento urbano, processo participativo, planejamento cicloviário.

\section{ABSTRACT}

In Brazil, one of the main elements that influence the structure of cities is the mobility model focused on individual motorized transportation. As a form of clash with contemporary urban paradigms, creative urban practices that come from popular initiatives (bottom-up) to tackle everyday problems are a growing world trend, and have great potential for transforming public spaces. The main objective of this work was to propose the use of tactical urbanism as a participatory tool in bicycle planning. The conception of the methodology was based on the analysis of the João Pessoa Cycle Plan through a collaborative methodological process, which supported the choice and application of the interventions. The research revealed that the insertion of tactical urbanism as a formal tool in urban planning can promote a new look at planning strategies and, consequently, foster a truly participatory process in the production of urban space.

Key words: Tactical urbanism, urban planning, participatory process, cycle planning. 


\section{INTRODUÇÃO}

As cidades e as relações que nelas se constituem, são fruto de um longo processo de transformação, seja ele espontâneo ou planejado. Como organismo mutante, a cidade se transforma na ação de cada agente, que compõem um campo amplo de necessidades, vontades e ações coletivas. Lefebvre (2000:43) afirma que "a cidade é a soma de indícios e indicações, fruto de um complexo conjunto de diferente ciência e relações sociais, econômica, seja na ação local, individual ou coletiva". No entanto, a sequência de decisões políticas no contexto urbano, quase sempre isoladas, sem continuidade e clareza do perfil de cidade que se deseja, advindos de diferentes vertentes de planejamento urbano combinados ao rápido crescimento populacional e ao inchaço demográfico nas grandes cidades podem ser considerados agentes dos problemas enfrentado no meio urbano de hoje.

Dentre as decisões políticas que podem comprometer a qualidade da vida urbana está a primazia dada ao automóvel nos sistemas de transportes e planos de mobilidade. Essa decisão fez com que em várias cidades, o planejamento urbano adquirisse um caráter rodoviarista, privilegiando a construção de rodovias e de subúrbios espraiados, afastados do centro e monofuncionais. Jacobs (1961) expôs sua inquietação a respeito de fundamentos do planejamento urbano e da reurbanização, desmistificando os problemas urbanos e indicando que estes, devem ser confrontados e revertidos juntamente com os processos que causaram à falência da cidade, pois são frutos do mal planejamento urbano baseado no ideal de cidades homogêneas fundamentadas na pureza (Ebenezer Howard), beleza (Daniel Burham) e funcionalidade (Le Corbusier).

No Brasil, um dos principais elementos a influenciar a estrutura das cidades é o modelo de mobilidade centrado no transporte motorizado individual, o qual se materializa como modelo de planejamento urbano. Por sua vez, Villaça (1999:173) explica que no Brasil "aquilo que nas últimas décadas tem sido denominado planejamento urbano (e que nas décadas de 30 e 40 se chamava urbanismo) é a ação do Estado sobre a organização do espaço intraurbano". Planejamento este, o qual têm ações principalmente voltadas para redesenho da infraestrutura das cidades a longo prazo e com custos elevados.

No entanto, essa forma de "fazer cidade" está cada vez mais insustentável por ter como objetivo final transformar a cidade a partir da lógica capitalista, com base em análises estatísticas, com horizontes de planejamento de longo prazo e oportunidades limitadas para o envolvimento dos cidadãos. Muitos urbanistas e formuladores de políticas públicas continuam trabalhando para melhorar a infraestrutura nas cidades, todavia, esse modelo de fazer melhorias muitas vezes é incompatível com as necessidades mais prementes da população. Ademais, seus processos de implementação são quase sempre em longo prazo e centrados em práticas de gestão que não viabilizam a construção coletiva por meio dos mecanismos de participação popular, tornando os resultados incapazes de fomentar as mudanças sociais e econômicas necessárias e compatíveis às problemáticas urbanas mais urgentes como, por exemplo: a redução do tempo de viagem origem $\mathrm{x}$ destino, a qualidade do transporte público coletivo, a eficiencia do sistema cicloviário e a qualidade dos passeios e espaços públicos. Tais questões, são necessidades cotidianas que possuem influência direta no crescimento econômico, na oferta dos serviços e na qualidade de vida da população.

Nesse contexto são bem vindas as práticas urbanas criativas que chegam a partir de iniciativas da população (bottom-up) para abordar problemas do cotidiano. Tais práticas estão em crescimento em vários contextos mostrando ter tem grande potencial na transformação dos espaços públicos e estilo de vida da população. São conhecidas por urbanismo tático, urbanismo de guerrilha, urbanismo pop-up, reparação da cidade ou urbanismo DIY. Dessa forma, essa proposta de trabalho procurou explorar o universo do Urbanismo Tático. Os americanos Mike Lydon e Anthony Garcia (2015:2) definem urbanismo tático como "uma abordagem para a construção e ativação de espaços públicos usando intervenções e políticas alcançáveis, de curto prazo e de baixo custo, o qual pode ser utilizado por uma gama de atores que inclui o governo, empresas e empresas sem fins lucrativos, grupos comunitários e cidadãos".

Assim, o processo de planejamento da cidade pode somar novas ferramentas de investigação sem, contudo, eliminar o modelo de planejamento urbano vigente, pois este ainda é relevante para os grandes serviços urbanos. Isso posto, nos parece positivo diversificar a forma de planejar com novas estratégias de planejamento e com envolvimento dos cidadãos na construção da cidade, dando a estes a chance de cultivar o sentimento de pertencimento ao local onde habitam. No entanto, apesar do momento de crise econômica e política no Brasil clamar por iniciativas rápidas e de baixo custo, o lugar para essas iniciativas no âmbito da prática de planejamento urbano e o papel do urbanista nessa decisão ainda é incerto, ou até mesmo desconhecido.

Dessa forma, a partir de uma inquietação pessoal quanto às condições de mobilidade ciclísticas em João Pessoa motivou o desenvolvimento dessa pesquisa, que teve como objetivo principal propor o uso do 
urbanismo tático como ferramenta participativa no planejamento cicloviário para promover ações de incentivo ao uso da bicicleta.

Diante do exposto, esse trabalho se apresenta como uma aposta de que o urbanismo tático e o seu viés participativo podem fomentar um novo olhar sobre o planejamento cicloviário e, consequentemente, impulsionar a apropriação dos espaços públicos da cidade de João Pessoa através de novas soluções para a mobilidade de bicicletas. Ele surgiu num momento oportuno, anterior à fase de implantação do Plano Cicloviário da Prefeitura Municipal de João Pessoa (PMJP) e, pode auxiliar como ferramenta de investigação e ação no espaço urbano, onde se utiliza de um conceito de Urbanismo Tático, que trabalha com melhora sócio-espacial, consciente e participativa.

\section{PLANEJAMENTO URBANO E A CIDADE DE JOÃO PESSOA}

As ferramentas para estimular o exercício da cidadania no meio urbano contemporâneo podem estar na combinação do planejamento de longo prazo com as estratégias de transformações rápidas econômicas. Nesse caso, o valor do Urbanismo Tático está no rompimento do impasse do que se chama de "processo do grande planejamento" com projetos e políticas que incrementam e que podem ser ajustados de acordo com as condições existentes, o que não acontece com as metas em longo prazo e em larga escala, os quais correm risco de paralisarem ou risco de deixarem de ser concluída por fatores diversos (Lydon \& Garcia, 2015).

Dessa forma, o urbanismo tático pode ser visto como uma possibilidade de ligação entre os planejadores municipais e os cidadãos, e essa união pode ser aceita como um grande avanço para a sociedade atual no qual os complexos desafios enfrentados vêm privando as pessoas do convívio e do uso dos espaços públicos. Lefebvre (2001) critica a sociedade burocrática de consumo e a forma de pensar o espaço urbano meramente como questões administrativas, técnicas e científicas, pois acarretam a alienação dos que ali habitam, uma vez que são apenas objetos e não sujeitos do espaço social. O crescente descompasso entre política governamental desatualizada e a demanda por infraestrutura e amenidades urbanas é um grande fator para a ascensão do Urbanismo Tático.

Tanto no pensamento de Lefebvre, como na definição do Urbanismo Tático explicada por Lydon \& Garcia o processo de transformação do espaço urbano é de responsabilidade principalmente da população, não importa em que escala, cabe ao coletivo manifestar, intervir e transformar o meio em que vive. Maricato (2000:169) afirma que "é evidente que não é possível reverter o rumo do crescimento das cidades sem reverter os rumos das relações sociais". Da mesma forma, Harvey (2008) questiona se o rumo que tomou a urbanização dos últimos 100 anos contribuiu para a qualidade de vida do cidadão e reconhece que inversão de valores do pensar as cidades como uma solução econômica e estratégica influenciou o modo de vida que desempenhamos nelas. Para Lydon \& Garcia (2015) a recente ascensão do Urbanismo Tático na América do Norte é sustentada por quatro grandes tendências e eventos: as pessoas voltando para a cidade, a Grande Recessão, a rápida ascensão da Internet e a crescente desconexão entre o governo e os cidadãos. Essa observação é válida também para diversas cidades do mundo e expõe a necessidade das cidades reformularem o modo como funcionam/planejam.

A cidade de João Pessoa-PB não é uma exceção, ela apresenta um cenário bastante deficiente de mobilidade, com carências do planejamento integrado entre transporte e uso do solo. Hoje, a cidade continua seguindo o modelo concebido há trinta anos pelo o Plano Diretor de Transportes Urbanos de João Pessoa PDTU (GEIPOT/1985), e ordinariamente, passa por modificações no seu sistema viário através de ações do tipo; duplicação de vias, alteração de sentido de ruas, construção de viadutos e outros. Segundo Oliveira (2006:186), "a relação entre o uso do solo e os transportes na cidade repercutiu não somente nos elevados custos de urbanização e das tarifas, como afetou também o comportamento da mobilidade urbana e os modos dos transportes utilizados pela população". A população opta diariamente pela utilização de veículos motorizados devido à má qualidade dos transportes públicos coletivos e a falta de prioridade para o transporte não motorizado.

Hoje, a cidade passa por um processo de construção do Plano Diretor de Mobilidade Urbana de João Pessoa (PlanMob-JP), que será gerido pela PMJP junto a um consórcio formado com três empresas, sendo um total de investimento de R\$ 3,3 milhões. O Plano de Mobilidade irá realizar um diagnóstico técnico das condições de mobilidade da cidade com os municípios vizinhos da microrregião e definir as diretrizes e propostas a médio e longo prazo (10 a 20 anos). Com isso, a iniciativa da construção do Plano Diretor de Mobilidade, representa uma esperança rumo a uma cidade que se desloca de forma mais segura, democrática e sustentável, bem como uma oportunidade para inserção do urbanismo tático no seu planejamento. Sendo pensados em conjunto governos e cidadãos, esse tipo de abordagem pode resultar no planejamento de uma 
cidade que valoriza a reapropriação dos espaços públicos, a reconquista das áreas centrais, a preservação ambiental e o reordenamento da mobilidade.

\section{METODOLOGIA E PROCESSO DE PARTICIPAÇÃO}

Pensar no urbanismo tático para a cidade de João Pessoa não é e nem será a solução definitiva da mobilidade cicloviária e ativação dos espaços públicos. Pois, dentre estas problemáticas, a cidade carece de infraestrutura básica, planejamento e integração, onde principalmente nos bairros periféricos é notável a falta de redes de esgoto sanitário e abastecimento de água potável, de energia elétrica pública e muitas vezes domiciliar e as vias de circulação. No quesito de mobilidade urbana a falta de investimento no modal de transporte ativo acentuam as dificuldades de se locomover na cidade e o processo de espraiamento urbano continua aumentando as distâncias e exigindo cada vez mais a utilização do veículo motorizado.

No entanto, pensar os diferentes locais da cidade em conjunto com a população de maneira participativa incide sobre a inclusão das minorias na tomada de decisões e, portanto, a construção de uma cidade mais justa. Fontes (2011:12) explica o conceito de amabilidade urbana "como um atributo do espaço amável, daquele que promove ou facilita o afeto e a proximidade, opondo-se ao individualismo por muitas vezes característico das formas de convívio coletivo contemporâneo". Na criação e posterior implantação de um plano cicloviário para a cidade de João Pessoa, não basta propor rotas isoladas de um processo onde ciclistas e motoristas apenas reconheçam essas rotas, mas sim, construir junto com a sociedade possibilidade da amabilidade nesse processo.

Uma política pública para o ciclismo urbano conta com intervenções de mobilidade na cidade como um todo, buscando incorporar critérios favoráveis para o tráfego de bicicletas. Para promover condições cicloinclusivas em uma cidade é essencial o desenvolvimento de um diagnóstico que determine a função, forma e uso das vias, tanto em nível de rede quanto em nível de desenho cicloviário, sendo este o responsável por determinar o tipo de infraestrutura cicloviária a ser adotada (ITDP, 2011). Para incorporar a bicicleta na rede viária da cidade é essencial que todas as rotas estejam em sintonia, assim, foram realizados os levantamentos dos dados que serviram de suporte para análise e sugestões do Plano Cicloviário de João Pessoa (PCJP - PMJP).

As ações participativas feitas para realização desse trabalho tiveram início desde a caracterização do uso da bicicleta na cidade de João Pessoa até a sua fase final de realização das intervenções. Para tanto, foram analisados pontos críticos do Plano Cicloviário de João Pessoa (Figura 1), consideradas sugestões da população advindas de um mapa colaborativo, de um questionário, de uma série de reuniões presenciais com grupo de ciclistas ativista e, também, de dados do Relatório Final 07 - Síntese, produzido pelo Consórcio Oficina - Setec International - Setec Hidrobrasileira contratado pela PMJP em parceria com o Banco Mundial (PMJP, 2014).

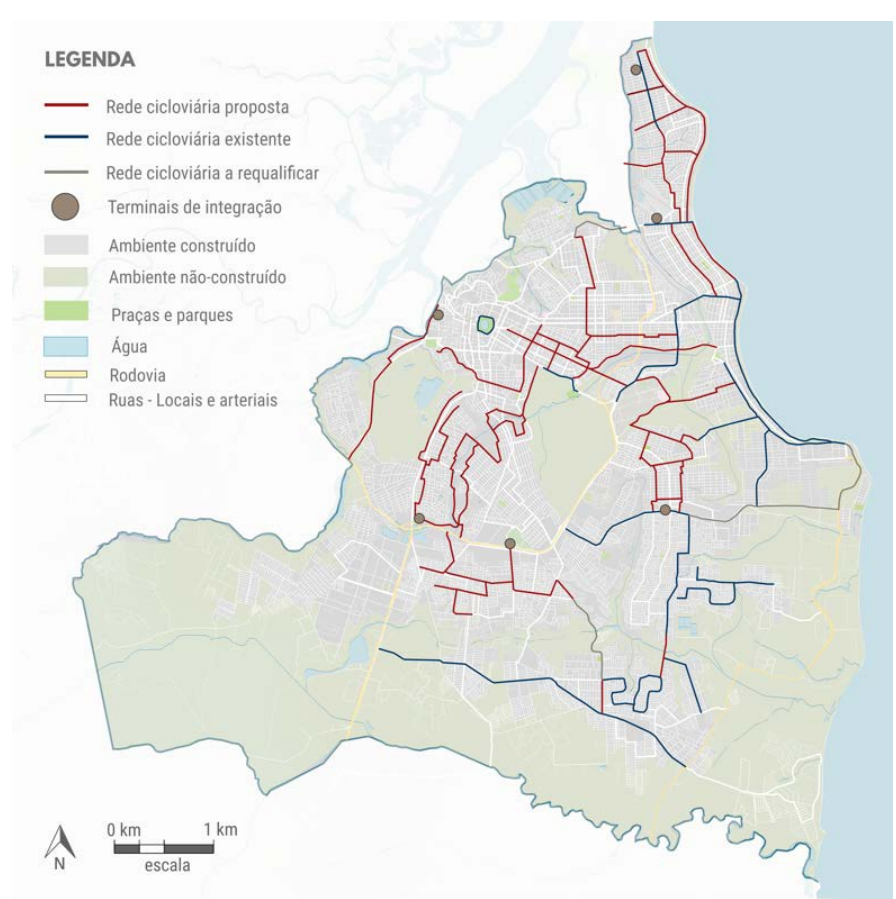

Figura 1: Mapa do Plano Cicloviário de João Pessoa

Elaborado pela autora a partir do Plano Cicloviário de João Pessoa da PMJP, sd 
A metodologia buscou examinar o contexto dos deslocamentos ciclísticos da cidade através de parâmetros estabelecidos na metodologia "Plano Cicloviário Participativo Local", desenvolvido pela ONG Holandesa I-CE (Interface for Cycling Expertise) em parceria com o Programa de Parcerias pela Bicicleta (Bicycle Partnership Program - BPP). A metodologia utiliza dois métodos holandeses de planejamento urbano: Otimização do Trânsito em uma Área Específica (Area Specific Optimization - OTAE) método para gerenciar o processo e o Planejamento Cicloinclusivo (Design for the bicycle) método de inclusão da bicicleta no planejamento urbano. (Figura 2).

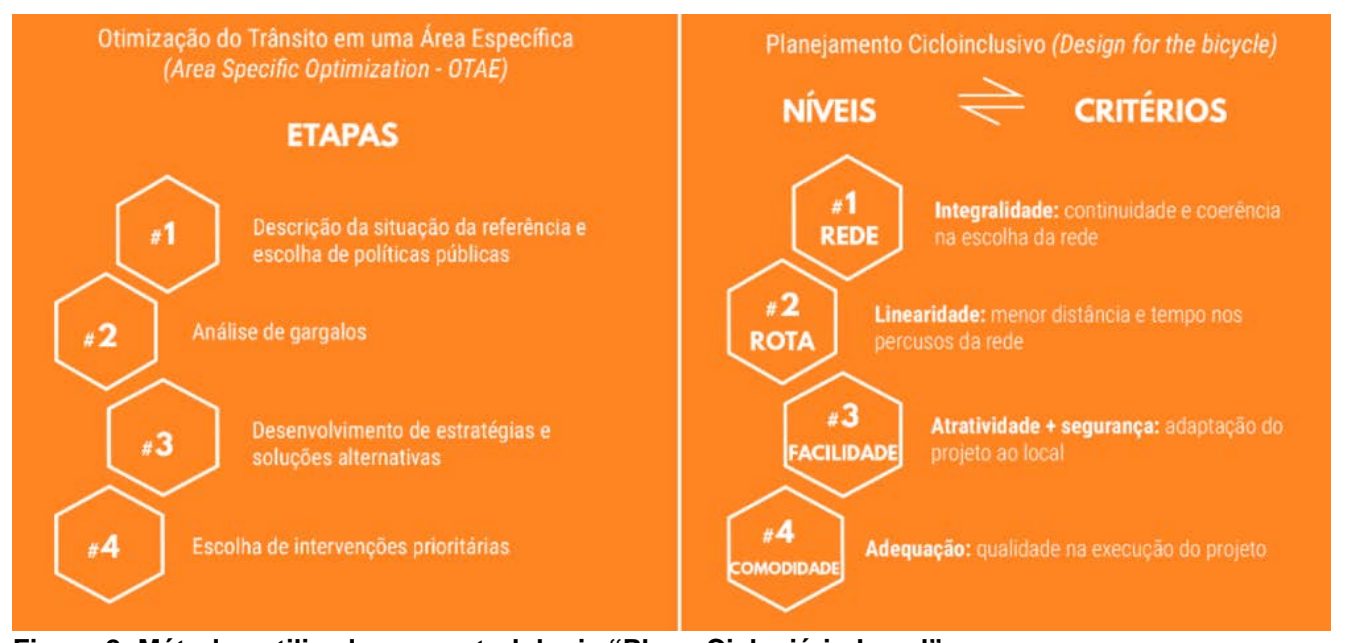

Figura 2: Métodos utilizados na metodologia "Plano Cicloviário Local"

Elaborado pela autora com base no CROW, e2001

É necessário entender que o processo de planejamento para o uso da bicicleta, necessita balancear cada uma das exigências expostas acima, tendo em vista uma abordagem de forma integral que avalia a infraestrutura cicloviária em diferentes níveis do desenho. Xavier [et al.] (2009) ressalta que o desenho compreensivo começa com o planejamento no nível da rede. Explica também que para melhorar a qualidade dos elementos da rede, diversos tipos de facilidades devem ser também introduzidos com moderação de tráfego, construção: inclusão de rotatórias, melhorias dos cruzamentos, construção de estacionamento para bicicletas, entre outros.

E por fim, todo o processo tem que procurar equilibrar estes elementos de transporte com características de uso do solo, como qualidade ambiental/paisagística, conexões com atividades atratoras e geradoras de viagens e considerações quanto a vias de caráter comercial. A combinação dos dois métodos com a participação da população é o diferencial da metodologia, pois em todas as fases existe a presença de diversos atores da sociedade. Experiências na cidade de Resende (117.391 habitantes) no estado do Rio de Janeiro e no Bairro da Tijuca (163 mil habitantes), localizado na zona norte do Rio de Janeiro, tiveram duração de três workshops e dois dias, respectivamente, após a mobilização e capacitação de pessoas para a participação do workshop.

O mapeamento do uso da bicicleta na cidade de João Pessoa e a análise do Plano Cicloviário de João Pessoa, foram feitos com a colaboração de 296 ciclistas da cidade. Adentrou-se nas particularidades através do método de avaliação pós-ocupação walkthrough, que proporcionou a avaliação in loco, possibilitou a identificação detalhada dos aspectos negativos e positivos das mesmas. Segundo Rheingantz [et al.] (2009:23), a "sua realização permite identificar, descrever e hierarquizar quais aspectos deste ambiente ou de seu uso merecem estudos mais aprofundados e quais técnicas e instrumentos devem ser utilizados". Dessa forma, as rotas cicloviárias da proposta foram registradas através de vídeos e fotografias e destacadas as descobertas mais relevantes a serem trabalhadas.

O resultado demonstrou que os ciclistas fazem uso frequente da bicicleta e que suas principais queixas se relacionam com a falta de infraestrutura adequada para a utilização da bicicleta na cidade. Concluiu-se que o Plano Cicloviário de João Pessoa possui trajetos que conseguem cumprir com os níveis de Rede e Rota e outros que estão em desacordo. Os níveis de Facilidade e Comodidade não foram possíveis avaliar, pelo fato do plano não oferecer detalhes o suficiente e também pelo fato da infraestrutura não está implantada. Como produto foi feito o mapa que reúne as recomendações dos níveis de Rota e Rede e as queixas advindas da vivência do ciclista, onde se observou áreas com alto volume de tráfego, com alta velocidade de veículos motorizados, cruzamentos de grandes avenidas, bem como as marcações de acidentes, de locais perigosos/hostil e de locais com difíceis travessias. 


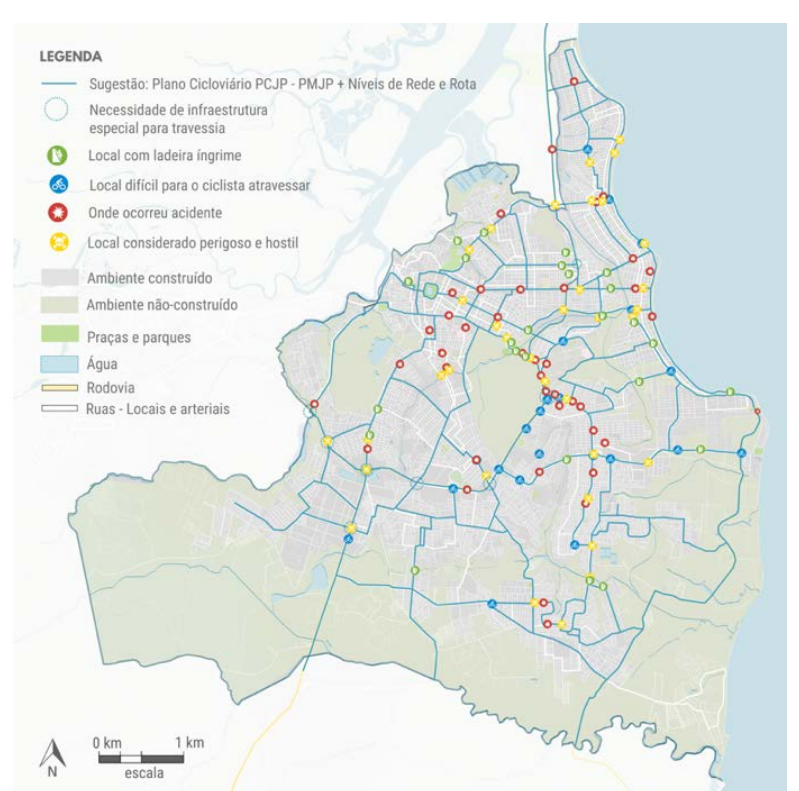

Figura 3: Mapa de recomendação de rotas na cidade de João Pessoa e apontamentos da população Elaborado pela autora

Esse mapa mostra a complexidade da criação de rotas cicloviárias e não teve a pretenção de ser visto como uma proposta definitiva, mas sim, despertar um novo olhar para o planejamento cicloviário na cidade de João Pessoa feito em conjunto com a população e de acordo com as reais necessidades do ciclista. É importante ressaltar que as rotas sugeridas são fruto de uma observação no qual o modal cicloviário está colocado como prioridade na política de mobilidade urbana, onde o planejamento da mobilidade urbana que prioriza a circulação do veículo motorizado individual foi desconstruído. Dessa forma, ressalta-se que uma infraestrutura cicloviária completa, cria condições em termos de eficiência no deslocamento, otimizando a capacidade física e psíquica e proporcionando a sensação de conforto e segurança do ciclista. Qualquer proposta de rede cicloviária deve prever a intervenção de certo número de vias de forma prioritária para garantir a mobilidade básica, no entanto, uma política efetiva deve prever a incorporação da bicicleta em todas as vias da cidade, partindo da premissa de que a rua é um espaço compartilhado por todos, é um espaço democrático.

Para a fase de intervenções o processo de participação se deu através do envolvimento com o orgão municiapal competente (SEMOB-JP) através da oportunidade de participação no Dia Mundial Sem Carro (22 de setembro) na cidade de João Pessoa, evento chamado "Na cidade sem meu Carro". O qual tem como objetivo principal estimular uma reflexão sobre o uso excessivo do automóvel, além de propor às pessoas que revejam a dependência que se criou em relação ao veículo motorizado individual, que em cidades do mundo todo são realizadas atividades em defesa do meio ambiente e da qualidade de vida. As reuniões junto a SEMOB-JP ocorreram semanalmente durante o mês de agosto e setembro nas quais foram discutidas as ações a serem realizadas. Ao longo das reuniões foram apresentadas e debatidas propostas de atrações e intervenções que poderiam fazer parte do dia, bem como a concretização das mesmas.

As propostas de intervenções buscaram se apropriar dos espaços públicos da cidade que em sua maioria ignoram as necessidades reais dos pedestres e ciclistas para dá prioridade aqueles que utilizam o veículo motorizado individual. As propostas de intervenções compreenderam um rol de ferramentas de urbanismo tático relacionadas com a mobilidade e melhoria no trânsito. As ferramentas foram distribuídas conforme as necessidades das áreas escolhidas e do seu entorno, compreendidas em: sinalização, ruas abertas, pintura de faixa de pedestre, ciclorota em cruzamentos, alargamento de calçadas, luta cicloativista, ciclovias temporárias, arte pública e feedback da população.

No contexto atual de comunicação e tecnologia, a forma mais rápida e eficiente encontrada para a divulgação das intervenções foram as redes sociais, elas foram essenciais nesse processo, o qual percorreu o meio digital até chegar ao presencial. As viabilizações das intervenções foram pensadas junto com o Escritório Modelo - TRAMA e com a colaboração dos estudantes foram executados os elementos pré-intervenção. E também, feita a divulgação das intervenções para a sociedade através da página do TRAMA. $O$ alcance do recrutamento via mídias digitais no evento "Experiência de intervenção tática em João Pessoa", possibilitou a presença de 29 colaboradores nas intervenções nos bairros dos Bancários e Manaíra, a página também divulgava o evento "Na cidade sem meu carro", promovido pela página da Prefeitura Municipal de João Pessoa que aconteceu na Rua Visconde de Pelotas no dia 22 de Setembro. 
O processo de construção das intervenções buscou alertar a comunidade sobre as deficiências dos espaços públicos que foram apontados e identificados pelos próprios cidadãos. E, posteriormente, foram criadas possibilidades de ação em comunidade que buscaram dar ferramentas simples para a população mostrar os seus anseios, as quais se concretizaram através da atividade de intervenção e uso do lugar concebido. Sendo esta, repensar formas de planejar a cidade e envolver os cidadãos na construção da cidade, dando a estes a chance de cultivar o sentimento de pertencimento ao local onde habitam.

\section{INTERVENÇÕES}

O "urbanismo tático" pode ser entendido como uma alternativa para as ferramentas formais de planejamento, através da implementação em curto prazo, do mínimo de gasto de recursos financeiros e da participação dos cidadãos. Estas podem permitir melhorias nas cidades rapidamente e colocam especialistas e cidadãos trabalhando juntos em projetos de planejamento. Este trabalho tem como produto final intervenções táticas em pontos estratégicos da futura rede cicloviária da cidade de João Pessoa. Os objetivos dessas intervenções foram estimular e incentivar a população e as comunidades locais ao uso da bicicleta como modal de transporte e ao uso do espaço público, bem como testar possíveis elementos da rede cicloviária. Para tanto, o entendimento do Plano Cicloviário de João Pessoa se fez fundamental nesse contexto de transformações.

As intervenções aqui apresentadas tiveram contribuição de diversos atores locais que se uniram em busca de fazer melhoria no espaço público. As intervenções foram possíveis através da contribuição da Prefeitura Municipal, SEMOB-JP, IESP, TRAMA-UFPB, UNIPÊ, FPB, Bike Anjo João Pessoa e Coletivo Cidade Bike.

\subsection{Cruzamentos Seguros}

A intervenção foi realizada na Av. Governador Flávio Ribeiro Coutinho com Av. Guarabira (Retão de Manaíra), teve o objetivo de requalificar o cruzamento da Avenida, transformando-o em um espaço mais seguro para pedestres e ciclistas e chamar atenção da problemática da mobilidade dos transportes ativos.

O Retão de Manaíra é uma importante avenida da cidade e já possui ciclofaixa. No entanto, as marcações de acidente, dificuldade de atravessar e de avenida considerada perigosa e hostil foi ocorrente, o que demonstra ser um local problemático para o ciclista. Em observações, notou-se que a ciclofaixa da Avenida não está bem conservada e é pouco visível pelo fato de existir sujeira. Percebeu-se também que é pouco respeitada pelos motoristas de veículos individuais, onde é recorrente a presença desses estacionados na ciclofaixa. A falta de marcação de continuidade da ciclofaixa nos cruzamentos, também torna o espaço menos respeitado e mais inseguro, pois os motoristas não percebem a presença do ciclista e acabam não dando a preferência pela passagem do mesmo, o que dá margem também para acidentes.

A viabilidade e a visibilidade da intervenção foram fatores importante na escolha, pois, dentre as intervenções propostas, essa localiza-se em uma Avenida com grande movimentação de veículos motorizados individuais e teve recorrente o número de marcações de problemas nos mapas colaborativos. Dessa forma, durante as reuniões com a SEMOB-JP a proposta foi apresentada e discutida, sendo colocada na programação do "Dia Mundial Sem Carro" por ter um cunho educativo com relação a mobilidade por transportes ativos e principalmente por proporcionar uma melhoria para a segurança dos que ali transitam.

A execução ocorreu no dia 20 de setembro entre 21:00 e 00:00, teve participação de 13 voluntários e os trabalhos ocorreram com o apoio dos agentes da SEMOB-JP na reorientação do trânsito (Figura 4). A intervenção foi prevista para permenacer durante 2 a 3 dias, dessa forma, utilizou-se tinta d'agua e as ferramentas para a pintura foram vassouras e esfregoções, todos os moldes feitos de papelão tinham sido preparados no dia anterior, o que facilitou o trabalho da equipe. A maior dificuldade encontrada foi o tempo de espera da tinta secar no asfalto, pois na mesma noite havia chovido e o asfalto ainda estava molhado. As placas foram feitas à mão, onde foi impresso e colada no papelão, sua colocação também foi feita de forma artesanal com barbante nos postes existentes. 


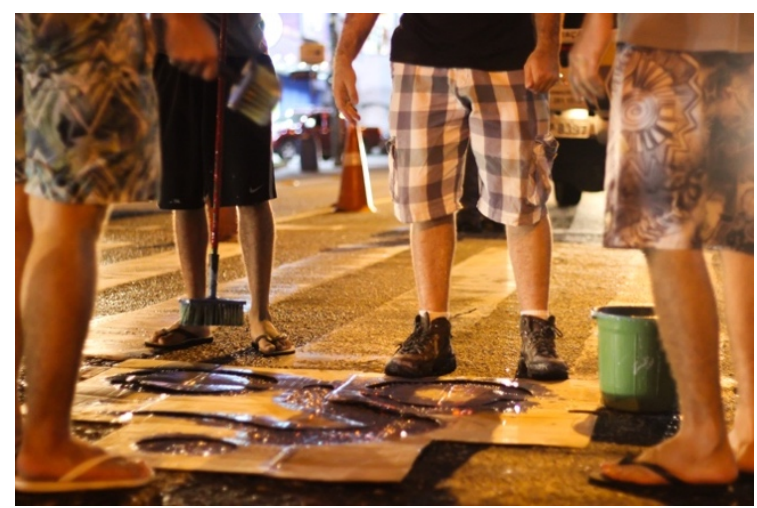

Figura 4: Dia de intervenção com pinturas Thiago Melo, 2017

O fato de ter sido uma atividade autorizada pelo poder público foi fundamental para o sucesso da execução da intervenção, tendo em vista o grande fluxo de veículos durante o processo. A ação teve êxito por fazer parte de um processo de conscientização, ao conferir novo sentido para o lugar a partir de uma mudança rápida, e criar uma rua mais amigáveis aos moradores. A utilização de cores foi fundamental para tonar a intervenção mais visível aos olhos dos motorista. Em conversas com os transeuntes foi possível extrair que a intervenção motivou as pessoas a repensarem seus hábitos quanto as pessoas que tinham menos espaços no trânsito, que muitas vezes são invisíveis aos olhos do motorista. Dessa forma, a reparação do cruzamento (Figura 5) se concretizou no sentido de significar um processo de requalificação iniciado pela sociedade, onde ela assumiu para si a tarefa de melhorar local onde habita.

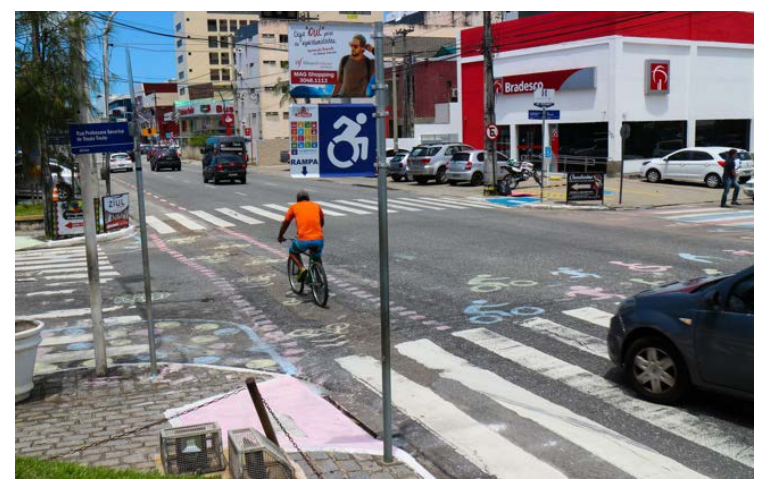

Figura 5: Retão de Manaíra no dia posterior à intervenção. Foto da autora, 2017

\subsection{Ruas Abertas}

A intervenção foi realizada na Rua Visconde de Pelotas, teve o objetivo de promover durante um dia espaços seguros para realizar atividades diárias como para andar a pé, de bicicleta, de skate e desenvolver atividades sociais (jogos, atividade culturais e esportivas), possibilitar o desenvolvimento da economia local e chamar a atenção relativamente aos efeitos negativos do automóvel na vida urbana. Essa é uma importante rua localizada no centro histórico da cidade que tem grande fluxo de pedestre devido ao número de comércio nela existente.

A experiência foi palco principal da comemoração do Dia Mundial Sem Carro na cidade de João Pessoa. Utilizou-se da ideia de intervenção de Ruas Abertas para fechar a rua para os carros (Figura 6), deixando aberta a receber atividades recreacionais. Após o processo de reuniões e organização do evento, a rua contou com diversas atrações que focavam na temática da mobilidade e no lazer de crianças e adultos.

A rua se transformou em uma grande praça, onde os entretenimentos estavam disponíveis entre 07:00 e 18:00. Contou com atividades como minicircuito de bicicletas, brinquedos infláveis, cinema no ônibus, oficina de reciclagem, oficina de desenho, exposições de desenho das crianças, oficina de Parklet, ponto de atendimento à saúde e atividades esportivas abarcaram públicos de todas as idades. O Ponto dos Cem Reis também recebeu pistas de skate e oficinas que ensinavam aos transeuntes e crianças a andar de skate e bicicleta. Um palco foi montado e várias atrações foram apresentadas nele, dentre elas, equipe circense, danças de rua, ciranda de roda e muita música para compor o dia. Os vendedores ambulantes também permaneceram no acrescentou mais um ponto positivo para a intervenção. 


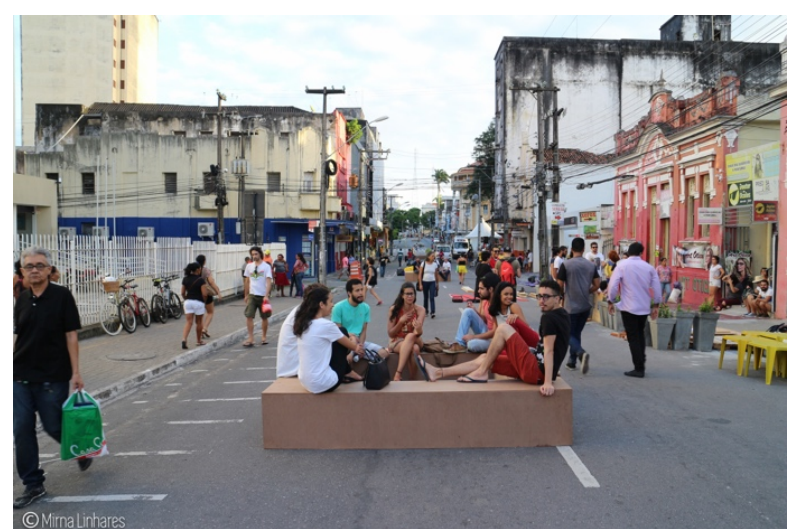

Figura 6: Rua Visconde de Pelotas no dia do Evento "Dia Mundial Sem Carro". Foto da autora, 2017

A ação de Rua Aberta foi bem recebida pelo público que aproveitou as atrações e, principalmente, pelas crianças que fizeram do local um verdadeiro espaço de diversão. A interação social foi sem dúvida o ponto alto da experiência, pois proporcionou as pessoas que passam diariamente pela aquela rua um novo olhar. No entanto, não se pôde deixar observar que certos hábitos não da noite para o dia. Muitas pessoas apesar de estarem caminhando por uma rua em que os carros não estavam transitando, ainda estavam condicionadas a andar nas calçadas e atravessar somente na faixa de pedestre (Figura 7). Atitudes como esta são motivos da promoção com mais frequência de Ruas Abertas na cidade de João Pessoa.

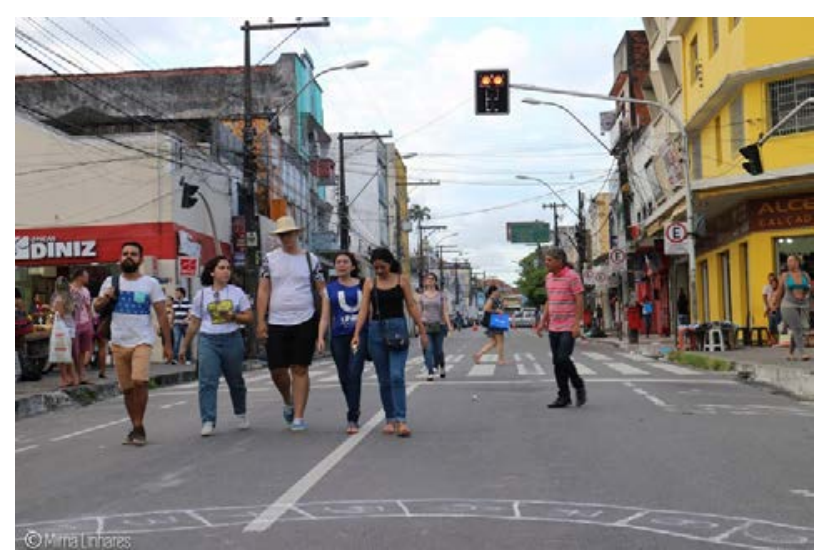

Figura 7: Atrativos infantis na Rua Visconde de Pelotas.

Foto da autora, 2017

É importante notar que a intervenção do tipo "Ruas Abertas" são uma ferramenta para a construção de uma sociedade mais fisicamente ativa e socialmente saudável e ainda, promove o mercado local provocando um impacto real nos negócios, no comércio e nas organizações localizadas ao longo da rua e, no caso da Rua Visconde de Pelotas representou um novo rumo para a do Centro da cidade.

\subsection{Passagem zig-zag}

A intervenção foi realizada na Av. Bancário João Rodrigues Alves, no bairro Brancários, teve como objetivo inserir uma faixa de pedestre de forma rápida e divertida, proporcionando a população uma travessia segura. A intervenção da faixa de pesdetres foi escolhida para execução pela urgência que essa ação tem na vida dos moradores do bairro. A avenida é local de fluxo intenso de veículos motorizados, bicicletas e pedestre, pois liga a zona Sul da cidade com os bairros ao norte e também está próxima à Universidade Federal da Paraíba-UFPB. A recorrência de marcações de acidentes, local perigoso e hostil e dificuldade na travessia foi abundante e a variedade de reclamações nos questionários chamou atenção para que fosse pensada uma intervenção naquela avenida.

Ao longo da avenida é notável a negligencia ao pedestre e ciclista enquanto a questão de deslocamento e travessias, possuindo calçadas que se amoldam mais aos carros do que as pessoas que ali transitam, pois servem também de estacionamento e a passagem que resta para os pedestres e ciclista são obstruídos e esburacados. O local escolhido foi o trecho próximo ao Carrefour, onde pedestre e ciclista fazem longas esperas para atravessar de um lado a outro da Avenida e correm risco de vida tendo em vista a alta velocidade que os carros alcançam naquela área. Durante as reuniões com a SEMOB-JP a ação foi muito bem recebida, 
reconhecendo a importância e necessidade da apropriação daquele espaço, principalmente por ser uma ação tomada por parte da sociedade.

Dessa forma, no dia 21 de setembro entre 21:00 e 01:00, com a participação de 15 voluntarios e o apoio na reorientação do trânsito da SEMOB-JP a intervenção foi executada. O tempo de duranção da intervenção era de 2 a 3 dias. O que foi utilizada foi tinta d'agua e as ferramentas para a pintura foram vassouras e esfregoções e o molde do ziz-zag feito de pvc foi preparado no dia anterior, o que proporcionou maior precisão no trabalho (Figura 8). A maior dificuldade nesse dia, se deu pelo grande fluxo de veículos na avenida e pelo fato de possuir apenas duas vias de cada sentido, a intervenção causou o transtorno maior no local. As placas também foram feitas e colocadas artesanalmente no local, nesse dia, também foi colado lamba-lambes ao longo de toda a avenida. Durante a execução, foi visível o interesse dos que ali passavam e paravam por alguns minutos para ajudar na ação ou apenas mostrar curiosidade e apoio à ação. Parte da tinta utilizada, foi doação de um morador, que se empenhou e incentivou a inciativa. O apoio dos agentes da SEMOB-JP foi fundamental para manter a segurança da equipe.

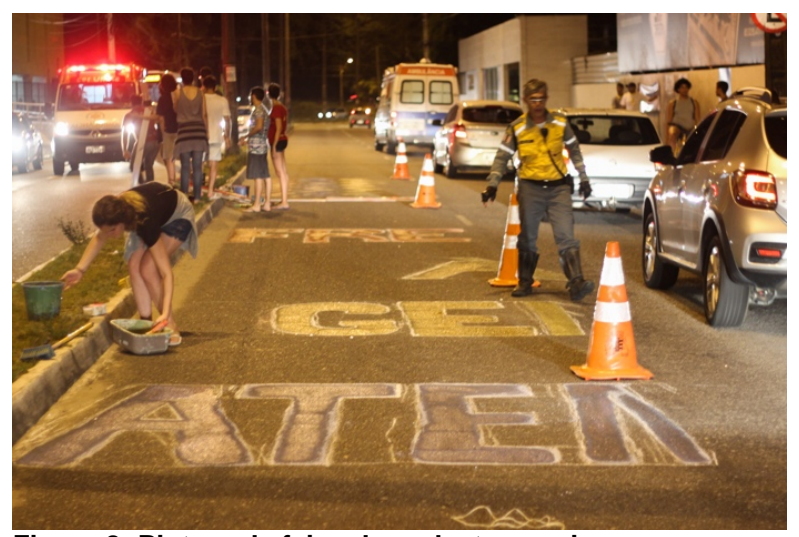

Figura 8: Pintura da faixa de pedestre e avisos

Yuri Ferraz, 2017

A intervenção foi muito bem recebida pelo público, já no dia anterior, se viu uma grande repercussão nas redes sociais que se falava da nova faixa de pedestre. Em observações foi possível notar que pedestres e ciclistas se apropriaram de fato do espaço oferecido e que a partir desse dia, passaram a se direcionar para atravessar na faixa de pedestre (Figura 9). No entanto, a falta de um agente da SEMOB-JP para orientar e educar os motorista dificultou o êxito por completo da intervenção, pois se percebeu muitas pessoas fazendo sinal de passagem e carros que negligenciavam o pedido. Depois de uma semana, ainda havia pintura remanecente, o que fez com que as pessoas continuassem a atravessar a avenida local onde havia sido pintada, no entanto, as placas que avisavam a respeito da faixa de pedestre para os motoristas, já haviam desaparecido.

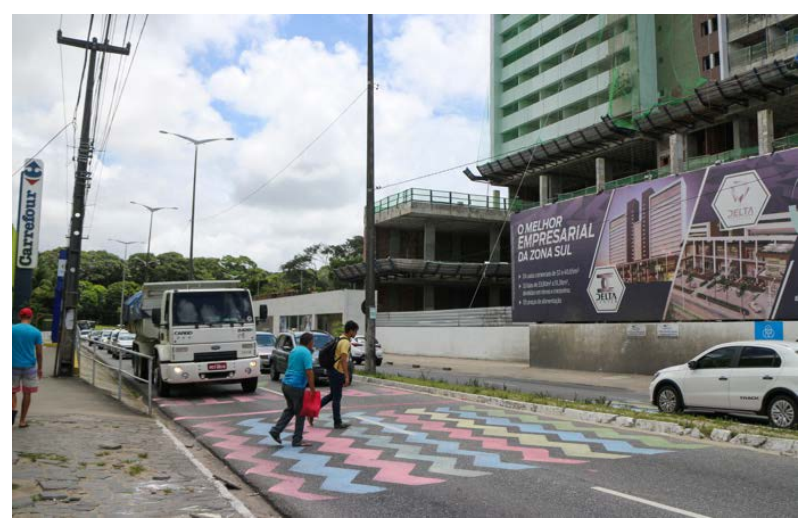

Figura 9: Foto do dia posterior à intervenção Foto da autora, 2017

Essa ação de urbanismo tático, apesar de ser simples e ter gastos mínimos, serviu para que a população mostrasse sua força como agente transformador da cidade. Diversos casos como esse já foram registrados em cidade mundo a fora, onde após a receptividade positiva da intervenção tática, moradores e líderes comunitários entravam com processos para implementação de uma faixa de pedestre formalizada. Essa também é uma oportunidade da Prefeitura municipal aproveitar o potencial que a população tem em se envolver no planejamento da cidade. 


\section{CONCLUSÃo}

Através das análises e das intervenções percebeu-se que a bicicleta na realidade brasileira é mistificada como um equipamento voltado para o lazer ou modalidade esportiva e como meio de transporte de classes menos favorecidas. Essa crença se deve à desvalorização cultural do transporte ativo em relação à super valorização do automóvel individual como um bem que representa progresso e prosperidade, fato constantemente reforçado pela indústria automobilística. Nesse caminho, desde a década de 1950 que o planejamento urbano passou a ser centrado nas grandes construções para o benefício dos que utilizam o transporte motorizado individual. A utilização da bicicleta como modal de transporte não está sendo considerada no planejamento urbano das cidades brasileiras, a infraestrutura cicloviária é irrelevante em meio à tantas rodovias, viadutos, pontes, etc. Diante dessa realidade, percebe-se uma reação por parte da própria população, ativistas e gestões públicas, no sentido de reverter esse processo, embora ainda de forma tímida e pontual. Hoje, é notável que o custo dessas políticas é muito alto, as cidades estão espraiadas, o espaço público negligenciado e as pessoas segregadas de acordo com suas classes sociais.

No entanto, quando se vivencia ou se observa experiências de outros países, nota-se a potencialidade que a bicicleta tem de transformar os espaços públicos das cidades e proporcionar qualidade de vida para aqueles que a utilizam. Um planejamento urbano centrado no transporte ativo é decisivo na transformação dos hábitos e da participação da população nas tomadas de decisões da cidade. O ciclista, diariamente vivencia experiências desafiadoras e a inquietação quanto a negligência do modal cicloviário na cidade de João Pessoa levou a investigar a utilização da bicicleta como modal de transporte na cidade. Relacionando-a com o planejamento urbano e as novas formas de fazer cidade, a qual coloca a bicicleta como meio de transporte, como motivo de luta ativista e como equipamento de retomada do espaço público.

Através da caracterização do planejamento cicloviário de João Pessoa e da utilização da bicicleta foi possível notar que o planejamento cicloviário nunca esteve efetivamente presente na construção da mobilidade urbana da cidade. Hoje, João Pessoa possui um Plano Cicloviário que apenas propõe rotas, sem detalhamento ou especificação do tipo de infraestrutura cicloviária proposta, não expõe um diagnóstico e não considera outros tipos de políticas públicas que beneficiam o modal cicloviário. Também foi possível perceber que os ciclistas entendem a cidade como um local hostil ao trajeto da bicicleta onde a sua segurança é constantemente ameaçadas por motoristas e onde sentem que a inserção do modal cicloviário no planejamento da cidade é ignorado pelos órgãos públicos. No entanto, é importante destacar que existem reações positivas na gestão pública, mas que precisam ser incorporadas como políticas públicas efetivas para as gestões futuras. Iniciativas colocadas pela SEMOB no ano de 2017, que encabeçou o evento, Na cidade sem meu carro - Dia 22 de Setembro e iniciou a construção participativa do Plano de Mobilidade de João Pessoa (PlanMob) devem ser enaltecidas e continuadas.

A utilização do conceito de urbanismo tático se fez importante para propor as ferramentas que auxiliem a comunidade na promoção de ações que pudessem incentivar o uso da bicicleta, trazer e enaltecer a apropriação do espaço público, e inclusive questionar as políticas de mobilidade cicloviária na cidade de João Pessoa. As intervenções propostas surgiram a partir de uma demanda colocada pelos ciclistas, e tiveram a intenção de sanar problemas colocando o baixo custo, rapidez e participação popular como principais pilares da transformação. As intervenções abordadas nesse trabalho se revelam como convites à um modelo de vida urbana mais sustentável, pensadas para a escala do pedestre e do ciclista para promover a proteção e priorização dos modais de transporte ativo e a apropriação dos espaços públicos da cidade através da execução das mesmas.

A partir das experiências táticas realizadas, identificaram-se diferentes aspectos da construção da cidade contemporânea frente ao urbanismo tático, onde sua realização utilizou-se da união dos órgãos municipais, comunidade acadêmica, comunidade civil organizada e da participação da sociedade. Foi possível perceber que as experiências permitiram maior engajamento da população na prática do planejamento e que serviram como uma fase experimental para uma possível implantação dos projetos, já que tiveram respostas positivas e se mostraram necessárias para a priorização dos modais ativos na cidade.

O desenvolvimento de uma metodologia que se baseou em princípios de planejamento cicloviário junto à participação popular foi fundamental para construção de um trabalho que deixa resultados reais. Desde o início, o método utilizou-se da premissa empírica, onde testar e experimentar as diversas formas de interação com a sociedade foi o maior desafio. A análise dos condicionantes, a interação via redes sociais e a articulação com a SEMOB-JP, durante o processo de análise e criação das intervenções, foi fundamental para a concretização e legitimidade das mesmas. As experiências táticas, no contexto deste trabalho, podem ser consideradas como um tema ainda incipiente, que necessita de maior articulação com a população, o estudo de metodologias mais inovadoras e de maiores contribuições da academia e do apoio e iniciativa do poder público. Pois, a efetiva transformação e quebra de paradigmas quanto ao planejamento urbano da 
cidade faz parte de um processo contínuo de multiplicação e de aperfeiçoamento que não ocorre "da noite para o dia" e que seriam necessárias diversas ações semelhantes para que essas estratégias ganhassem mais força e visibilidade, bem como a introdução de novos arranjos institucionais com à incorporação efetiva de ferramentas colaborativa.

A maior lição que o urbanismo tático traz é a possibilidade de tentativa e erro, juntamente com sua efemeridade. Os processos tradicionais de planejamento urbano nem sempre são adaptativos e resilientes o suficiente para enfrentar as condições sociais e econômicas em constante mudança nas cidades contemporâneas. A atual incerteza econômica, política e ambiental requer novos métodos de operação. Isso sugere um desejo contínuo de processos de construção de cidades que permitam a criação democrática do espaço por todos os cidadãos e a necessidade de espaços flexíveis que promovam trocas de experiências e permitam o inesperado. Além disso, o desejo crescente dos cidadãos de serem agentes transformadores de suas cidades não pode ser ignorado.

Apesar das estratégias de urbanismo tático serem inicialmente conceituadas como iniciativas de baixo para cima, através da ação cidadã, investigar a apropriação do poder público e de planejadores pode significar um ganho para ambas as partes. Dessa forma, é necessário que hajam esforços por parte dos profissionais envolvidos no planejamento e na gestão das cidades em incluir os processos coletivos de transformação do espaço. Diante do exposto, ressalta-se que a inserção do urbanismo tático como ferramenta formal no planejamento urbano pode fomentar um novo olhar sobre as estratégias de planejamento e mobilidade da cidade e, consequentemente, impulsionar a participação da população na construção da cidade e apropriação dos espaços públicos, buscando um processo verdadeiramente participativo que norteiam a produção do espaço urbano.

O trabalho acadêmico desenvolvido se lançou e se arriscou no caráter propositivo, que proporcionou aprofundar na teoria e experimentar a interação academia/sociedade/poder público. Como indicações para futuros trabalhos, coloca-se o desafio de investigar a maior interação entre sociedade e planejador/poder público para que se possa explorar diversas formas de permuta de estratégias. Um aprendizado que esse trabalho deixa é que o planejador precisa escutar os anseios da sociedade, ir a campo e testar as possibilidades antes da implantação permanente do projeto, pois as abordagens experimentais podem ser muito úteis, tanto para melhorar o projeto concebido dentro de quatro paredes, quanto para promover a liderança cidadã e o desenvolvimento da comunidade local, e encorajar novas formas de desenvolvimento econômico.

\section{BIBLIOGRAFIA}

ANTP (2012) Associação Nacional de Transportes Públicos. Transporte Humano - cidades com qualidade de vida. São Paulo: ANTP.

ARANTES, O., VAINER, C. e MARICATO, E (2000). A cidade do pensamento único: desmanchando consensos. Petrópolis: Vozes.

ARY, J, C. A (1984). Estudos de Transporte Cicloviário; vol. 4 (instruções para planejamento). Brasília: GEIPOT.

BAUMAN, Z. (2009). Confiança e Medo na Cidade. Rio de Janeiro: Jorge Zahar Ed.

BANCO INTERAMERICANO DE DESENVOLVIMENTO (BID) (2014). Plano de Ação João Pessoa Sustentável. João Pessoa.

BRASIL, M. das C. (2005). PlanMob. Caderno de Referência para Elaboração de Plano de Mobilidade Urbana. Brasilia: Ministério Das Cidades.

- (2016). SEMOB Secretaria Nacional da Mobilidade Urbano, WRI, Brasil. Caderno Técnico para Projetos de Mobilidade Urbana - SISTEMAS DE PRIORIDADE AO ÔNIBUS. Brasilia: Ministério Das Cidades.

- (2007). Plano de Mobilidade por Bicicleta nas Cidades, Coleção Bicicleta. Brasilia, DF: Ministério Das

Cidades. 
BOARETO, R. (org) (2010) A bicicleta e as cidades: como inserir a bicicleta na política de mobilidade urbana. São Paulo: Instituto de Energia e Meio Ambiente.

CHAPADEIRO, F. C (2011). Limites e potencialidades do planejamento cicloviário: um estudo sobre a participação cidadã. Dissertação de Mestrado. Brasília: ENC/FT/UnB.

CROW (e2011). Record 27: Manual de Diseño para el Tráfico de Bicicletas. Holanda: Ede.

GEHL, J (2013). Cidades para pessoas. São Paulo: Perspectiva.

GEIPOT - Empresa Brasileira de Planejamento de Transporte (2001). Planejamento cicloviário: diagnóstico nacional. Brasília.

HARVEY, D. (2013). A Liberdade da Cidade: En HARVEY, D. et al. Cidades rebeldes (27-34). São Paulo: Boitempo.

— (2014). Cidades rebeldes: do direito à cidade à revolução urbana. São Paulo: Martins Fontes.

ITDP-México (2011). Ciclociudades - Manual Integral de Movilidad Ciclista para Ciudades Mexicanas - Red de Movilidad en Bicicleta III.

FONTES, A. S. (2011). Intervenções temporárias, marcas permanentes: a amabilidade nos espaços coletivos de nossas cidades. Dissertação de Mestrado. Rio de Janeiro: UFRJ / FAU.

KARSSENBERG, H. (org.) (2015). A cidade ao nível dos olhos: lições para os plinths. Porto Alegre: EDIPUCRS.

LEITE, C. e AWAD, J. di C. M. (2012). Cidades sustentáveis, cidades inteligentes: desenvolvimento sustentável num planeta urbano. Porto Alegre: Bookman.

LEFEBVRE, H. (e2001). O Direito à Cidade (1̣a edição: 1968, título origina: Le Droit à la Ville). São Paulo: Centauro.

LUDD, Ned. (Org.) (2005). Apocalipse motorizado: a tirania do automóvel em um planeta poluído. São Paulo: Conrad Editora do Brasil.

LYDON, M. e GARCIA, A. (2015). Tactical urbanism: short-term action for long-term change.. Washington: Island Press.

LYDON, M. et al (2012). Tactical Urbanism: Short-term Action Long-term Change (Vol. 2). New York City: The Street Plans Collaborative.

JACOBS, J. (2011) Morte e vida de grandes cidades. São Paulo: WMF Martins Fontes.

LYDON, M., GARCIA, A (2015). Tactical urbanism: short-term action for long-term change. Washington: Island Press.

MILLER, K. F (2007). Designs on the Public: The Private Lives of New York's Public Spaces. Minneapolis: University of Minnesota Press.

NACTO, National Association of City Transportation Officials (2011). Urban Bikeway Design Guide. New York: NACTO.

OLIVEIRA, J. L. A. de (2006). Uma Contribuição aos Estudos Sobre a Relação Transporte e Crescimento Urbano: O Caso de João Pessoa. Dissertação de Mestrado. João Pessoa: PPGEUA/UFPB. 
PREFEITURA MUNICIPAL DE JOÃO PESSOA (Org.) (2014). Oficina Consultores Associados - Setec Internacional - Setec Hidrobrasileira. Apoio à estratégia de mobilidade urbana na cidade de João Pessoa: Rf 07 - Síntese. João Pessoa: SEMOB.

VILLAÇA, F (1999). Uma contribuição para a história do planejamento urbano no Brasil. In: DEÁK, Csaba. São Paulo: Universidade Federal de São Paulo.

SHIFFER, S. R. (orgs.) (1999). O processo de urbanização no Brasil. (170-243). São Paulo: FUPAM/EDUSP. SÁNCHEZ, FERNANDA. (1999). POLÍTICAS URBANAS EM RENOVAÇÃO: Uma Leitura Crítica Dos Modelos Emergentes. Revista B. Estudos Urbanos e Regionais. 115-132.

TRIBUNAL DE CONTAS DO ESTADO DA PARAÍBA (2012). Relatório de Auditoria Operacional em Mobilidade Urbana. João Pessoa.

XAVIER, G. N. A (2007). O cicloativismo no Brasil e a produção da lei de política nacional de mobilidade urbana. Revista Eletrônica dos Pós-Graduandos em Sociologia Política da UFSC, 122-145.

Sites:

Para mais informações consultar o site da ABRACICLO: http://www.abraciclo.com.br/2016/1057-producaode-bicicletas-registra-crescimento-de-13-6-em-outubro. (Acesso em: 05/03/2017).

Para mais informações consultar o site da $\mathrm{ABCP}$ - Associação Brasileira de Cimento Portland: http://www.solucoesparacidades.com.br/wpcontent/uploads/2014/03/AF_Inic\%20Insp02_ciclo\%20tijuca_ Print.pdf. (Acesso em: 06/05/2017).

Para mais informações consultar o site CNU: https://www.cnu.org/sites/default/files/cnucharter_portuguese.pdf>. (Acesso em: 25/04/2015). Para mais informações consultar o site Revista Piauí: http://piaui.folha.uol.com.br/materia/o-direito-acidade/. (Acesso em 04/05/2017).

Para mais informações consultar o site IBGE:

http://cidades.ibge.gov.br/painel/frota.php?lang=\&codmun=0\&search=| |infogr\%E1ficos:-frota-municipalde-ve\%EDculos'. (Acesso em: 05/03/2017).

Para mais informações consultar o site Vitruvius:

http://www.vitruvius.com.br/revistas/read/arquitextos/07.082/262>. (Acesso em: 25/042/2015).

Para mais informações consultar o site MOBILIDADE URBANA JOÃO PESSOA:

http://mobilidadejp.org/bicicleta/. (Acesso em: 05/05/2017).

Para mais informações consultar o site PREFEITURA MUNICIPAL DE JOÃO PESSOA:

http://www.joaopessoa.pb.gov.br/secretarias/semob/pac-mobilidade-urbana/>. (Acesso em: 05/05/2017). 